\title{
Spark Plasma Sintering and Densification Mechanisms of Antimony-Doped Tin Oxide Nanoceramics
}

\author{
Junyan Wu, ${ }^{1}$ Fei Chen, ${ }^{1}$ Qiang Shen, ${ }^{1}$ Julie M. Schoenung, ${ }^{2}$ and Lianmeng Zhang ${ }^{1}$ \\ ${ }^{1}$ State Key Lab of Advanced Technology for Materials Synthesis and Processing, Wuhan University of Technology, \\ Wuhan 430070, China \\ ${ }^{2}$ Department of Chemical Engineering and Materials Science, University of California Davis, CA 95616, USA
}

Correspondence should be addressed to Lianmeng Zhang; lmzhang@whut.edu.cn

Received 22 February 2013; Revised 18 April 2013; Accepted 23 April 2013

Academic Editor: Bikramjit Basu

Copyright (C) 2013 Junyan Wu et al. This is an open access article distributed under the Creative Commons Attribution License, which permits unrestricted use, distribution, and reproduction in any medium, provided the original work is properly cited.

\begin{abstract}
Densification of antimony-doped tin oxide (ATO) ceramics without sintering aids is very difficult, due to the volatilization of $\mathrm{SnO}_{2}$, formation of deleterious phases above $1000^{\circ} \mathrm{C}$, and poor sintering ability of ATO particles. In this paper, monodispersed ATO nanoparticles were synthesized via sol-gel method, and then ATO nanoceramics with high density were prepared by spark plasma sintering (SPS) technology using the as-synthesized ATO nanoparticles without the addition of sintering aids. The effect of $\mathrm{Sb}$ doping content on the densification was investigated, and the densification mechanisms were explored. The results suggest that ATO nanoparticles derived from sol-gel method show good crystallinity with a crystal size of $5-20 \mathrm{~nm}$ and Sb is incorporated into the $\mathrm{SnO}_{2}$ crystal structure. When the SPS sintering temperature is $1000^{\circ} \mathrm{C}$ and the Sb doping content is 5 at. $\%$, the density of ATO nanoceramics reaches a maximum value of $99.2 \%$. Densification mechanisms are explored in detail.
\end{abstract}

\section{Introduction}

Because of their high electrical conductivity combined with chemical stability and corrosion resistance, antimony-doped tin oxide (ATO) materials are widely used in numerous applications such as catalytic and gas-sensing applications to monitor toxic gas emissions, as electrodes in the glass industry and as transparent conductive oxide (TCO) films [1-4]. Recently, ATO ceramics with high density (>95\%) and high electrical conductivity have become target candidates for depositing TCO films in substitution of the more conventional indium tin oxide (ITO) films [5].

However, the densification of ATO ceramic is very difficult because surface diffusion and evaporation-condensation limit densification $[6,7]$. Long heating times required for conventional sintering (pressureless sintering and hot pressing) usually cause evaporation of $\mathrm{SnO}_{2}$ and lead to particle coarsening and low density. The sintering problem is further complicated by the high vapor pressure of $\mathrm{SnO}$, the formation of deleterious intermediate phases, and decomposition of the ATO system at temperatures above $1000^{\circ} \mathrm{C}$ [8]. Adding additives such as $\mathrm{ZnO}, \mathrm{CuO}$, and $\mathrm{MnO}_{2}$ can promote densification by a liquid-phase mechanism [9-11], but the secondary phases formed in these cases adversely affect the electrical conductivity.

Spark plasma sintering (SPS) has the potential to obtain fully dense materials at low temperature and with a rapid sintering rate, which can prevent the formation of deleterious intermediate phases and reduce the evaporation of $\mathrm{SnO}_{2}$. Furthermore the spark discharge could activate the particles to improve densification [12, 13]. Many researchers have reported the enhanced densification of $\mathrm{SnO}_{2}$-based ceramics prepared by SPS [14, 15]. Scarlat et al. [14] prepared ATO ceramics using the field-assisted sintering technique (FAST) with ATO powders obtained by solid phase synthesis. The relative density (92.4\%) was enhanced compared with the density of ATO ceramics sintered by conventional sintering technique (61.3\%), but it is still too low for a target used to prepare TCO films using magnetron sputtering method. Zhang et al. [15] used the SPS technique to fabricate ATO 
ceramics with high density of $97.4 \%$ using monodispersed ATO nanoparticles synthesized by the hydrothermal method. Compared to Scarlat et al.s results, the high density of ATO ceramics obtained by Zhang et al. can be contributed to the higher activation energy of ATO nanoparticles. However, Zhang has only reported the sintering behavior of ATO ceramic with 5 at.\% doping content of Sb. The sintering mechanism as well as the relationship between Sb doping content and densification behavior is not clear. Besides, as a conductive material, the effect of electrical conductivity on the sintering behavior and densification of ATO ceramic should not be ignored during the large electrical current sintering of SPS.

In this paper, monodispersed ATO nanoparticles were synthesized by the sol-gel method. Then, SPS with low temperature sintering and rapid sintering rate was used to obtain ATO ceramics with high density, without the incorporation of sintering aids. Finally, the densification mechanisms associated with SPS consolidation of bulk ATO ceramics were investigated.

\section{Experimental}

The ATO nanoparticles were prepared using sol-gel method. A precursor solution was synthesized using tin (IV) tetrachloride $\left(\mathrm{SnCl}_{4},>98 \%\right)$, antimony chloride $\left(\mathrm{SbCl}_{3}\right)$, anhydrous ethanol $\left(\mathrm{C}_{2} \mathrm{H}_{5} \mathrm{OH},>99.7 \%\right)$, and citric acid (CA) in a three-necked flask. The solution was refluxed at $70^{\circ} \mathrm{C}$ for $5 \mathrm{~h}$ with a vigorous stirring and then aged at $30^{\circ} \mathrm{C}$ for $48 \mathrm{~h}$ to get a gel. Finally, the gel was dried at $80^{\circ} \mathrm{C}$ in a vacuum oven for $24 \mathrm{~h}$ and then calcined in furnace at $500^{\circ} \mathrm{C}$ for $3 \mathrm{~h}$.

The SPS system (SPS-1050, Sumitomo Coal Mining Co, Yokohama, Japan) was used in the present investigation. The ATO nanoparticles were loaded in a $20 \mathrm{~mm}$ inner diameter graphite die, and then the die was transferred into the SPS machine. The pulse pattern was kept constant and consisted of twelve pulses (with a pulse duration of $3.3 \mathrm{~ms}$ ), followed by two periods of zero current. The applied axial pressure was $40 \mathrm{MPa}$ from the beginning of the heating step to the duration time, then it was unloaded to $0 \mathrm{MPa}$ during the cooling step. All samples were sintered at $1000^{\circ} \mathrm{C}$ (which is below the formation temperature of some deleterious intermediate phases during sintering) with a heating rate of $100^{\circ} \mathrm{C} / \mathrm{min}$ and dwell durations up to $3 \mathrm{~min}$ in vacuum $(\sim 20 \mathrm{~Pa})$.

The density of the sintered ATO ceramics was tested by the Archimedes method in water. The phase structures of the ATO nanoparticles and sintered ceramics were investigated by X-ray diffraction (XRD, Rigaku Ultima III) with $\mathrm{CuK} \alpha$ radiation. The sample was scanned from $20^{\circ}$ to $80^{\circ}(2 \theta)$ in steps of $0.05^{\circ}$. The crystallite size is calculated by the full width at half maximum (FWHM). The microstructures of the ATO nanoparticles and sintered ceramics were observed in a field emission scanning electron microscope (FE-SEM, Hitachi S-4800) and a transmission electron microscope (TEM, JEM-2100F STEM/EDS). The oxidation states of Sb were determined by X-ray photoelectron spectroscopy (XPS, VG Multilab 2000). During XPS analysis, a Mg/Al double anode X-ray was used as the excitation source.

\section{Results and Discussion}

3.1. Phase Composition and Microstructure of ATO Nanoparticles. Figure 1 shows the XRD patterns for ATO nanoparticles with different $\mathrm{Sb}$ doping concentrations and pure $\mathrm{SnO}_{2}$ nanoparticles. It can be seen that, with antimony content varying from 0 to 10 at.\%, ATO nanoparticles show the presence of only one crystalline phase structurally related to cassiterite, which indicates that the $\mathrm{SnO}_{2}$ lattice can accommodate 10 at. $\% \mathrm{Sb}$ atoms without significant changes in the structure [16]. With increasing Sb content, the peaks show little shift to the lower $2 \theta$ values, which indicates that $\mathrm{Sb}$ is incorporated into the $\mathrm{SnO}_{2}$ crystal structure. The crystallite size determined from the $\mathrm{SnO}_{2}$ (110) plane by FWHM is approximately $4.6 \mathrm{~nm}, 5.8 \mathrm{~nm}, 9.1 \mathrm{~nm}$, and $16.8 \mathrm{~nm}$ for ATO nanoparticles with 1 at.\%, 3 at.\%, 5 at.\%, and 10 at.\% Sb, respectively.

Figure 2 illustrates the TEM morphology of ATO nanoparticles with 5 at.\% Sb and 10 at.\% Sb. It is clear that the as-synthesized ATO nanoparticles show good crystallinity. The crystallite size of ATO nanoparticles with 5 at.\% Sb is $\sim 10 \mathrm{~nm}$, while the crystallite size of ATO nanoparticles with 10 at. $\% \mathrm{Sb}$ is $\sim 20 \mathrm{~nm}$, which is in agreement with crystallite size estimated by FWHM. This similarity indicates that the ATO nanoparticles synthesized by the sol-gel method are monodispersed. The small difference in crystallite size with different $\mathrm{Sb}$ doping concentration may contribute to the segregation of $\mathrm{Sb}$ to the surface of ATO particles, which ultimately affect the grain growth of particles [17]. The monodispersed ATO nanoparticles indicate high activation energy and good sintering potential, which may enhance the densification of ATO ceramics.

\subsection{Densification and Sintering Behavior of ATO Nanoceram-} ics. The SPS process used to consolidate the ATO nanoceramics (without the use of sintering aids) was carried out at $1000^{\circ} \mathrm{C}$ for a holding period of $3 \mathrm{~min}$ in vacuum at a heating rate of $100^{\circ} \mathrm{C} / \mathrm{min}$. Figure 3 shows the sintering behavior of pure $\mathrm{SnO}_{2}$ nanoparticles and as-synthesized ATO nanoparticles. Figure 3(a) illustrates displacement, displacement rate, and temperature curves as a function of the sintering time, while Figure 3(b) illustrates the densification curves converted from displacement by considering the relative densities of sintered samples [18, 19]. The slight shrinkage for ATO nanoparticles at the initial sintering stage can be seen clearly from Figure 3(a), while no shrinkage for $\mathrm{SnO}_{2}$ nanoparticles can be observed at the same stage. The slight shrinkage indicates the activation of ATO nanoparticles due to spark discharge, and this phenomenon will be further illustrated in Section 3.4. Furthermore, ATO nanoparticles show higher displacement rate than pure $\mathrm{SnO}_{2}$ nanoparticles at about $700^{\circ} \mathrm{C}$, which indicates enhanced sintering potential of ATO nanoparticles, especially ATO nanoparticles with 5 at.\% Sb. On the other hand, it can be seen obviously in Figure 3(b) that the ATO nanoparticles containing 5 at.\% Sb show a higher density than the other two samples at the same sintering temperature.

The lattice parameters and density data of the sintered ATO nanoceramics are provided in Table 1. For comparison, 


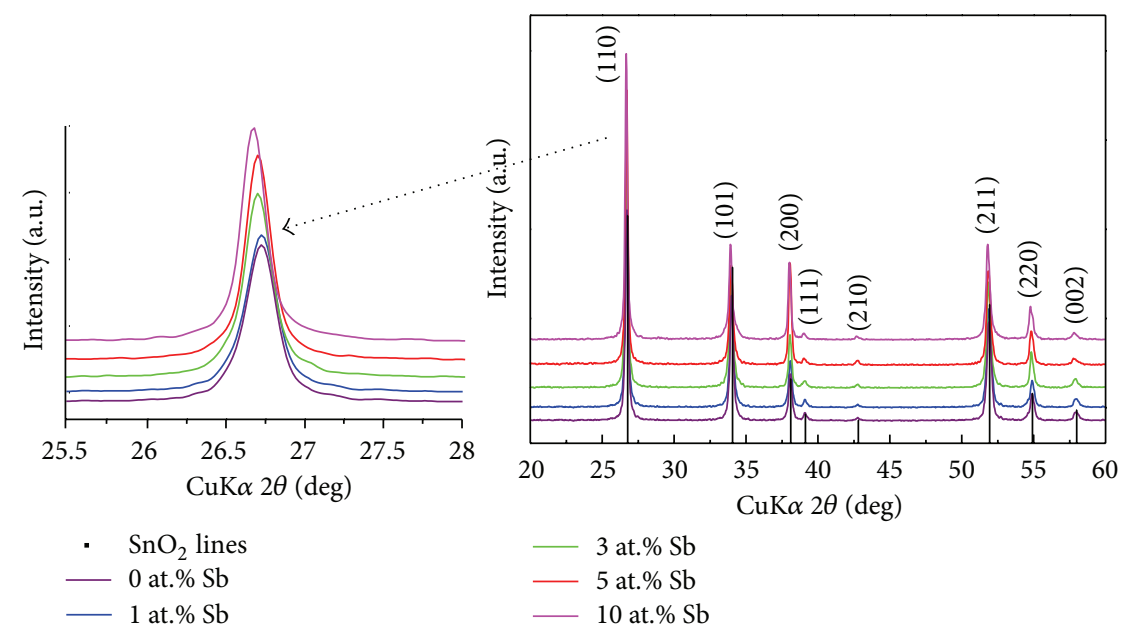

FIGURE 1: XRD patterns for ATO nanoparticles with different Sb doping concentrations.

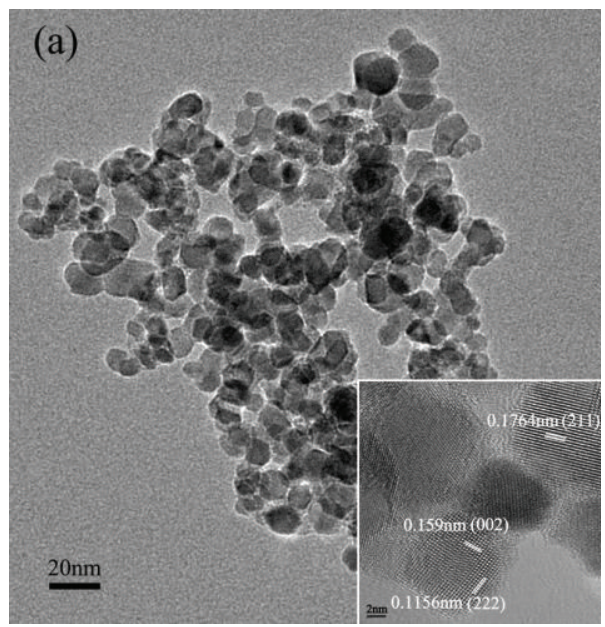

(a)

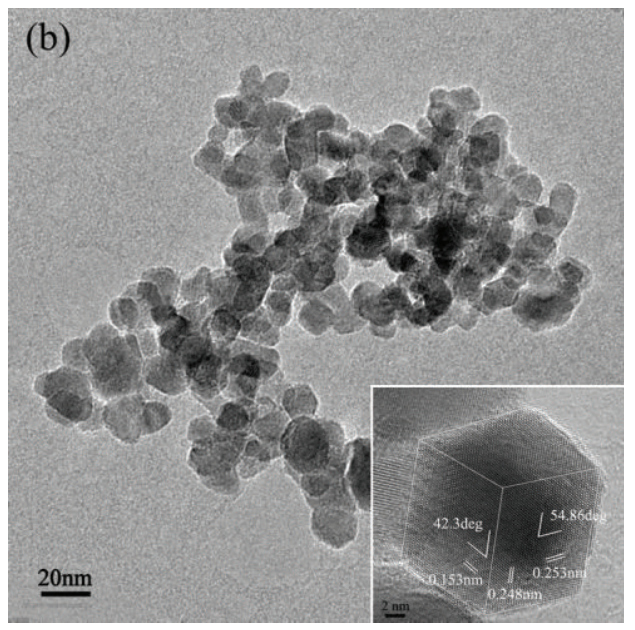

(b)

Figure 2: TEM morphology of ATO nanoparticles with (a) 5 at.\% Sb, (b) 10 at.\% Sb.

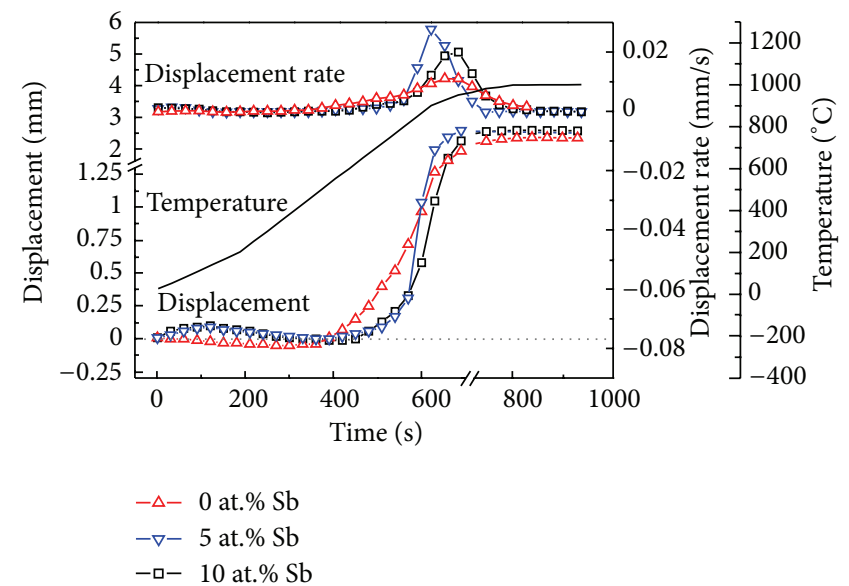

(a)

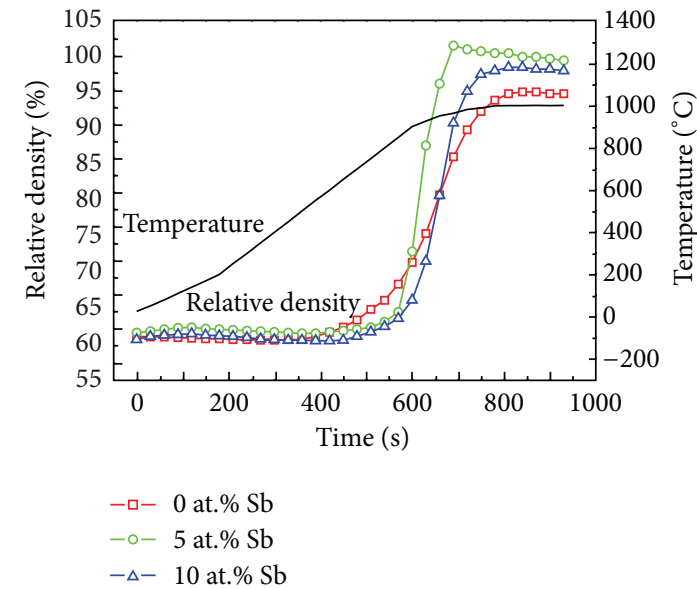

(b)

FIGURE 3: Sintering behavior of pure $\mathrm{SnO}_{2}$ nanoparticles and as-synthesized ATO nanoparticles: (a) displacement, displacement rate, and temperature curves as a function of sintering time, (b) relative density and temperature curves as function of sintering time. 
TABLE 1: Lattice parameters and density data of the sintered ATO nanoceramics.

\begin{tabular}{|c|c|c|c|c|c|c|}
\hline Sample & $a=b(\AA)$ & $c(\AA)$ & $V\left(\AA^{3}\right)$ & $d_{\text {theor }}\left(\mathrm{g} / \mathrm{cm}^{3}\right)$ & $d_{\exp }\left(\mathrm{g} / \mathrm{cm}^{3}\right)$ & $d_{\text {rel }}(\%)$ \\
\hline Pure $\mathrm{SnO}_{2}^{\dagger}$ & 4.7382 & 3.1871 & 71.552 & 6.993 & 6.599 & 94.4 \\
\hline 1 at. $\% \mathrm{Sb}$ & 4.7405 & 3.1898 & 71.682 & 6.987 & 6.71 & 96.1 \\
\hline 3 at. $\% \mathrm{Sb}$ & 4.7468 & 3.1905 & 71.89 & 6.95 & 6.73 & 96.8 \\
\hline 5 at. $\% \mathrm{Sb}$ & 4.7486 & 3.1955 & 72.057 & 6.944 & 6.889 & 99.2 \\
\hline 10 at. $\% \mathrm{Sb}$ & 4.749 & 3.221 & 72.622 & 6.89 & 6.732 & 97.7 \\
\hline
\end{tabular}

$V$ is the volume of the ATO crystal lattice, $d_{\text {theor }}$ is the theoretic density calculated by the lattice parameters, $d_{\exp }$ is the experimental density tested by the Archimedes method, and $d_{\text {rel }}$ is the relative density calculated as $d_{\exp } / d_{\text {theor }}$.

${ }^{\dagger}$ Pure $\mathrm{SnO}_{2}$ : JCPDS Card number 41-1445.

equivalent data for pure $\mathrm{SnO}_{2}$ are also included. It is clear that both $a$ and $c$ lattice parameters increase with increasing $\mathrm{Sb}$ doping concentration. These slight lattice distortions of the cassiterite $\mathrm{SnO}_{2}$ indicate that $\mathrm{Sb}$ is incorporated into the tin oxide lattice to form the ATO solid solution. Furthermore, the as-sintered ATO nanoceramics exhibit high density (96$\left.99 \% d_{\text {theor }}\right)$ under the selected SPS conditions, while the density of pure $\mathrm{SnO}_{2}$ ceramic is only $94.4 \%$. With the increase in Sb doping concentration from 0 at.\% to 10 at.\%, the density first increases then decreases. When Sb doping concentration is 5 at.\%, the density reaches the maximum value of $99.2 \%$ which is in agreement with the SPS sintering behavior shown in Figure 3.

3.3. Phase Composition and Microstructure of ATO Nanoceramics. Figure 4 shows the XRD patterns of sintered ATO nanoceramics with different $\mathrm{Sb}$ doping concentrations. The $\mathrm{XRD}$ spectra show that all peaks are characterized as the cassiterite $\mathrm{SnO}_{2}$ (JCPDS Card number 41-1445), which indicates that the sintered nanoceramics maintain the character of the ATO nanoparticles and no apparent phase change occurs. The pure and consistent phase of cassiterite $\mathrm{SnO}_{2}$ before and after sintering implies that the low temperature sintering of SPS successfully prevents the formation of deleterious intermediate phases and the decomposition of the ATO system. The slight shift in peak position with different Sb doping concentration is in agreement with the increases in lattice parameters. The XRD data shows some differences before and after sintering, which may attribute to the transformation of $\mathrm{Sb}^{3+}$ to $\mathrm{Sb}^{5+}$ during sintering [20].

Representative SEM micrographs of the sintered ATO nanoceramics with different $\mathrm{Sb}$ doping concentrations are provided in Figure 5. It is observed that the as-sintered ATO nanoceramics are nearly fully dense with no obvious porosity. The grain sizes of the sintered ATO nanoceramics are less than $100 \mathrm{~nm}$, and the grain size increases with increasing Sb doping concentration. When the Sb doping concentration varies from 1 at. $\%$ to 10 at.\%, the grain size increases from $20 \mathrm{~nm}$ to $100 \mathrm{~nm}$. The variable grain sizes may be due to the segregation of $\mathrm{Sb}$ to the surface of the ATO nanoparticles. With increasing $\mathrm{Sb}$ doping concentration, $\mathrm{Sb}$ segregation is known to occur as trivalent $\mathrm{Sb}$ (III) at the surface of ATO particles [21]. Trivalent Sb (III), as a cationic dopant with oxidation states lower than $\mathrm{Sn}^{4+}$, will act as a sintering additive to promote densification and grain growth [22].
Therefore, considering the $\mathrm{Sb}$ segregation, the grain size and density of the sintered ATO nanoceramic will increase with increasing Sb doping concentration. However, it can be seen from Figure 3 and Table 1 that the ATO nanoceramic with 5 at.\% Sb shows a higher displacement rate and higher density than the ATO nanoceramic with 10 at.\% Sb. Thus, the densification mechanisms for SPS-consolidated ATO nanoceramic cannot simply be attributed to the mechanism of adding $\mathrm{Sb}$ as a sintering additive.

3.4. Densification Mechanisms in ATO Nanoceramics. From the SPS point of view, the passage of electrical current depends on the electrical conductivity of the powder compact. In case of an insulating powder, the major part of the current passes through the graphite die, with a small fraction passing through particles. While for a conducting powder, the current will pass through the powder [23]. $\mathrm{SnO}_{2}$ is an n-type semiconductor with low electrical conductivity, and the conductivity will be improved by the addition of dopants such as Sb ions [24, 25]. Thus, a comparatively larger fraction of the total current will pass through the ATO powder compact compared with the $\mathrm{SnO}_{2}$ powder compact. The electrical resistivity values of $\mathrm{SnO}_{2}$ (with no $\mathrm{Sb}$ ) and ATO will also be shown in Figure 7. Therefore, spark discharges in the void spaces become more frequent in the ATO powder compact. The slight shrinkage and higher displacement rate of ATO nanoparticles shown in Figure 1 indicate the passage of current through the sample and the frequent spark discharge in void spaces, as further investigated in the following.

In an effort to investigate the densification mechanisms further, an ATO nanoceramic sample containing 5 at.\% Sb was removed from the SPS unit after reaching only $700^{\circ} \mathrm{C}$. This sample was evaluated using SEM and EDS, as shown in Figure 6. As shown in Figure 6(a), the spark discharges generate special grains (see region $\mathrm{A}$ ) in the gaps between the particles. No such grains were observed in the starting nanoparticles. The EDS results in Figure 6(b) suggest that the molar ratios of $\mathrm{Sb} / \mathrm{Sn} / \mathrm{O}$ for the different regions of the microstructure are different. The molar ratios for the region far from the gaps (see region C) are $1 / 19 / 40$, which is quite in agreement with the molar ratios for the raw particles. On the other hand, the Sn and O contents in the region on the gaps' edge (see region $\mathrm{B}$ ) are much smaller than that in the starting nanoparticles, with a molar ratio of 1/15/20. 


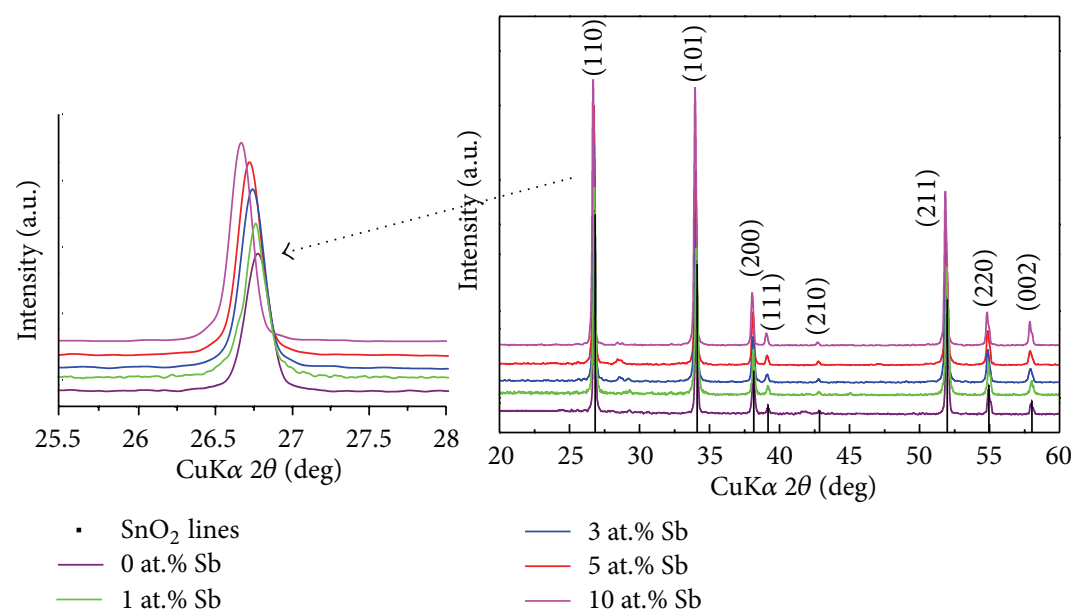

FIGURE 4: XRD patterns for sintered ATO nanoceramics with different Sb doping concentrations.

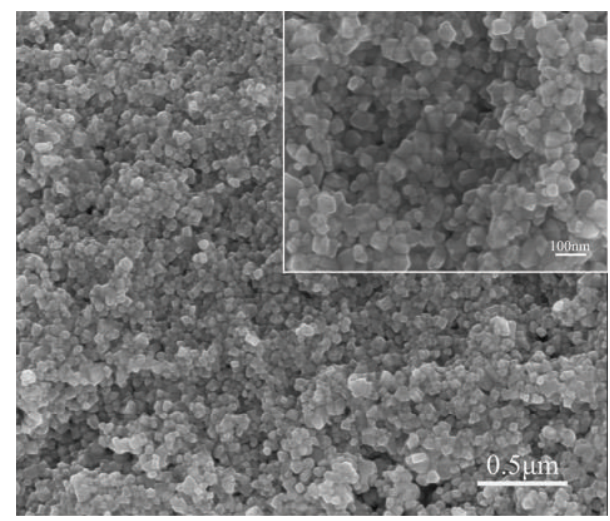

(a)

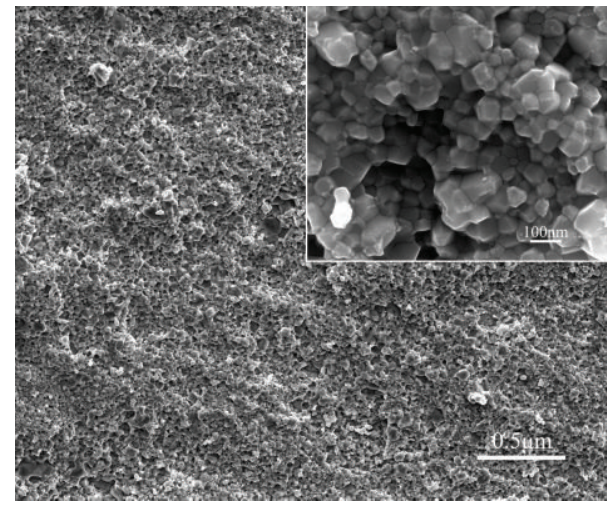

(c)

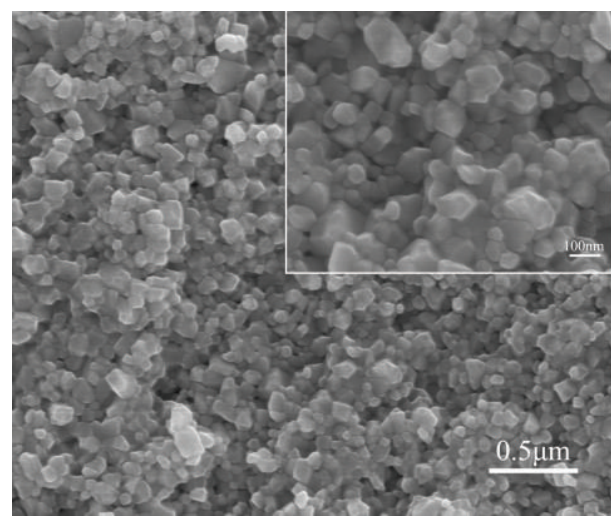

(b)

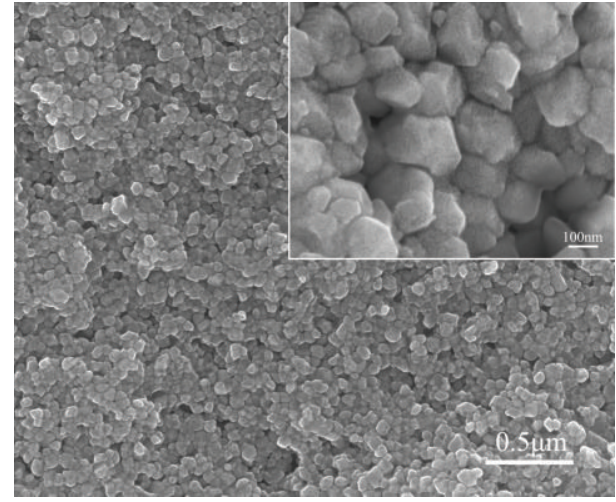

(d)

Figure 5: SEM micrographs of sintered ATO nanoceramics with different Sb doping concentrations: (a) 1 at.\% Sb, (b) 3 at.\% Sb, (c) 5 at.\% Sb, and (d) 10 at.\% Sb.

Many researchers have reported the effect of spark discharge during SPS sintering [26-28]. Particularly, Wu et al. have claimed that the discharge and high local temperature near the pores accelerate the reaction between raw materials [27]. On the other hand, Park et al. [7] have reported the possibility of $\mathrm{SnO}_{2}$ to evaporative decompensate into $\mathrm{SnO}(\mathrm{g})$ and $\mathrm{O}_{2}(\mathrm{~g})$ during spark plasma sintering. Thus, the different molar ratios suggest that, on the edge of the gaps, $\mathrm{SnO}_{2}$ decomposes into $\mathrm{SnO}(\mathrm{g})$ and $\mathrm{O}_{2}(\mathrm{~g})$ then condenses as $\mathrm{SnO}_{x}$ in the gaps by the spark discharge. Therefore, SPS discharges in the void spaces enhance the mass transport, which ultimately enhances densification.

Figure 7 shows the electrical resistivity of the sintered ATO nanoceramics with different Sb doping concentrations. 


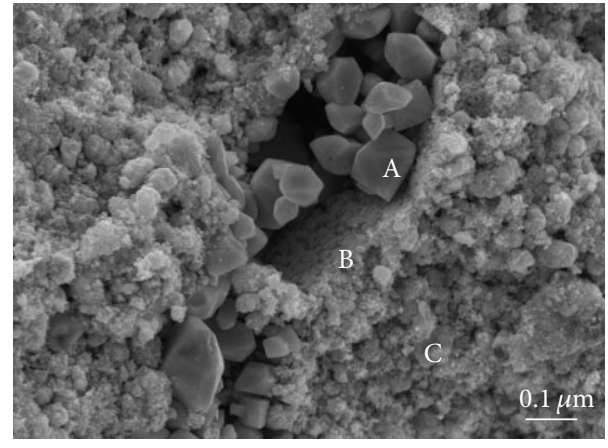

(a)

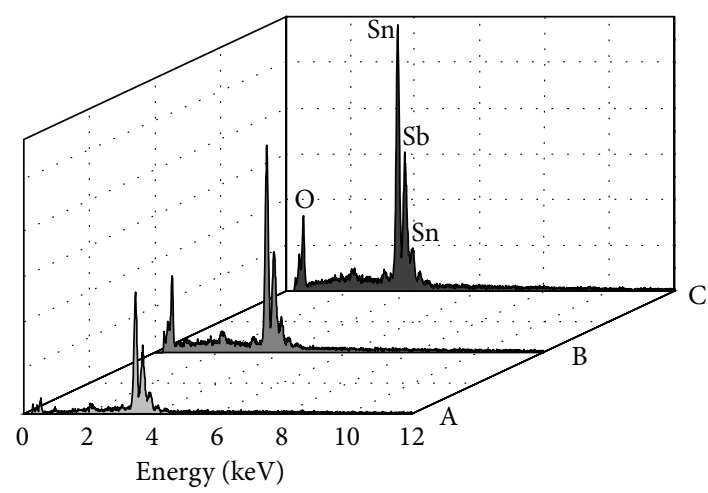

$\square \mathrm{A}$
$\square \mathrm{B}$
$\mathrm{C}$

(b)

FIGURE 6: SEM micrograph and EDS spectra for ATO nanoceramic containing 5 at.\% Sb, after SPS sintering to $700^{\circ} \mathrm{C}$.

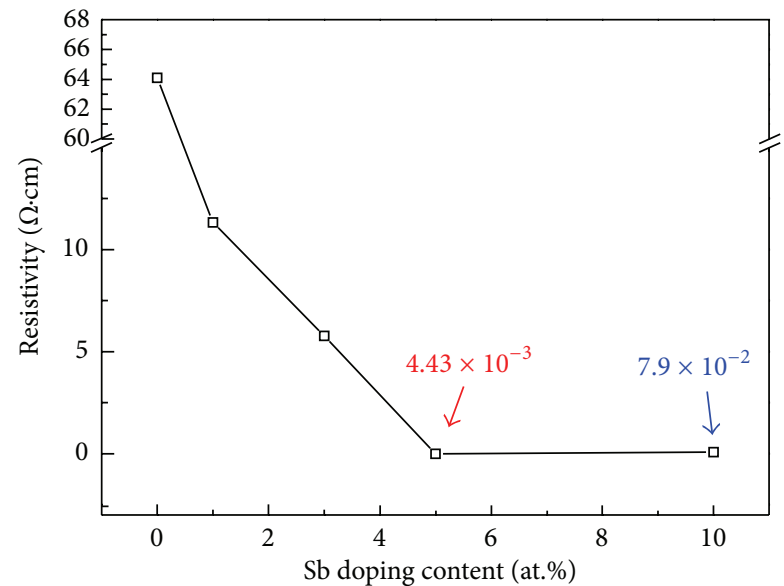

FIGURE 7: The electrical resistivity of sintered ATO nanoceramics with different Sb doping concentrations.

It can be seen that the electrical resistivity decreases with increasing $\mathrm{Sb}$ doping concentration and reaches a minimum value of $4.43 \times 10^{-3} \Omega \cdot \mathrm{cm}$ when the Sb doping concentration is 5 at.\%. The low electrical resistivity of the sintered ATO nanoceramic with 5 at.\% Sb suggests more current passed through the sample and more mass transport occurred due to SPS discharge in the void spaces. This phenomenon explains the high displacement rate for the ATO nanoparticles with 5 at.\% Sb, shown in Figure 3, which leads to the highest density of $99.2 \%$ for the sintered ATO nanoceramic containing 5 at.\% $\mathrm{Sb}$.

Although some researchers have reported the enhanced properties of SPS-prepared ATO ceramics, the density obtained by Park et al. [7] is around 95\% and is $92.4 \%$ by Scarlat et al. [14], which are lower than our results. Other researchers have prepared dense ATO ceramics with density of $>98 \%$ using hot pressing sintering, by adding sintering aids such as $\mathrm{ZnO}, \mathrm{CuO}$, and $\mathrm{MnO}_{2}$ [9-11], but the additive phases deteriorate their electrical properties. From the previous discussion, the high density of SPSconsolidated ATO ceramics can be attributed to three factors: (a) monodispersed ATO nanoparticles with little amount of $\mathrm{Sb}$ segregation at the surface provide high sintering potential and high surface activation; (b) low temperature sintering of SPS avoids the need for sintering aids and prevents the formation of deleterious intermediate phases and the decomposition of the ATO system, and the fast sintering rate reduces the evaporation of $\mathrm{SnO}_{2}$; and (c) semiconducting ATO nanoparticles enable more current to pass through the sample during sintering and SPS discharge in the void spaces enhances the mass transport, which further enhances densification.

\section{Conclusions}

Monodispersed ATO nanoparticles were prepared via solgel method. Antimony is incorporated into the $\mathrm{SnO}_{2}$ crystal structure in concentrations of 1 at. $\%$, to 10 at. $\%$ and the ATO nanoparticles show good crystallinity with crystallite sizes on the order of 5-20 nm. Near full density ATO nanoceramics were obtained without the addition of sintering aids by applying the SPS process at $1000^{\circ} \mathrm{C}$ with a holding time of $3 \mathrm{~min}$ and a heating rate of $100^{\circ} \mathrm{C} / \mathrm{min}$ using the assynthesized ATO nanoparticles. The highest density achieved in the sintered ATO nanoceramic was $99.2 \%$ when the $\mathrm{Sb}$ doping concentration was 5 at.\%. The high density of the SPS consolidated ATO nanoceramics is attributed to three factors: (a) monodispersed ATO nanoparticles with little amount of $\mathrm{Sb}$ segregation at the surface provide high sintering potential and high surface activation; (b) low temperature sintering of SPS prevents the formation of deleterious intermediate phases and the decomposition of the ATO system, and the fast sintering rate reduces the evaporation of $\mathrm{SnO}_{2}$; and (c) semiconducting ATO nanoparticles enable more current to pass through the sample during sintering and SPS discharge 
in the void spaces enhances the mass transport, which further enhances densification.

\section{Acknowledgments}

This work is supported by the International Science \& Technology Cooperation Program of China (no. 2011DFA52650), the 111 Project (B13035), and the Fundamental Research Funds for the Central Universities in China.

\section{References}

[1] W. Göpel and K. D. Schierbaum, " $\mathrm{SnO}_{2}$ sensors: current status and future prospects," Sensors and Actuators B, vol. 26, no. 1-3, pp. 1-12, 1995.

[2] W. Germain, H. P. Wilson, and V. E. Archer, Kirth-Othamer Encyclopedia of Chemical Technology, vol. 23, WileyInterscience, New York, NY, USA, 3rd edition, 1983.

[3] I. Saadeddin, B. Pecquenard, J. P. Manaud et al., "Synthesis and characterization of single- and co-doped $\mathrm{SnO}_{2}$ thin films for optoelectronic applications," Applied Surface Science, vol. 253, no. 12, pp. 5240-5249, 2007.

[4] K. Ravichandran and P. Philominathan, "Fabrication of antimony doped tin oxide (ATO) films by an inexpensive, simplified spray technique using perfume atomizer," Materials Letters, vol. 62, no. 17-18, pp. 2980-2983, 2008.

[5] M. Seo, Y. Akutsu, and H. Kagemoto, "Preparation and properties of Sb-doped $\mathrm{SnO}_{2} /$ metal substrates by sol-gel and dip coating," Ceramics International, vol. 33, no. 4, pp. 625-629, 2007.

[6] T. Kimura, S. Inada, and T. Yamaguchi, "Microstructure development in $\mathrm{SnO}_{2}$ with and without additives," Journal of Materials Science, vol. 24, no. 1, pp. 220-226, 1989.

[7] W. J. Park, W. Jo, D. Y. Kim, and J. H. Lee, "Enhanced densification of pure $\mathrm{SnO}_{2}$ by spark plasma sintering," Journal of Materials Science, vol. 40, no. 14, pp. 3825-3827, 2005.

[8] N. Dolet, J. M. Heintz, M. Onillon, and J. P. Bonet, "Densification of $0.99 \mathrm{SnO}_{2}-0.01 \mathrm{CuO}$ mixture: evidence for liquid phase sintering," Journal of the European Ceramic Society, vol. 9, no. 1, pp. 19-25, 1992.

[9] M. S. Castro and C. M. Aldao, "Characterization of $\mathrm{SnO}_{2}$ varistors with different additives," Journal of the European Ceramic Society, vol. 18, no. 14, pp. 2233-2239, 1998.

[10] I. Saadeddin, H. S. Hilal, B. Pecquenard et al., "Simultaneous doping of $\mathrm{Zn}$ and $\mathrm{Sb}$ in $\mathrm{SnO}_{2}$ ceramics: enhancement of electrical conductivity," Solid State Sciences, vol. 8, no. 1, pp. 7-13, 2006.

[11] S. Mihaiu, O. Scarlat, G. Aldica, and M. Zaharescu, " $\mathrm{SnO}_{2}$ electroceramics with various addditives," Journal of the European Ceramic Society, vol. 21, no. 10-11, pp. 1801-1804, 2001.

[12] Z. A. Munir and D. V. Quach, "Electric current activation of sintering: a review of the pulsed electric current sintering process," Journal of the American Ceramic Society, vol. 94, pp. $1-19,2011$.

[13] M. Omori, "Sintering, consolidation, reaction and crystal growth by the spark plasma system (SPS)," Materials Science and Engineering A, vol. 287, no. 2, pp. 183-188, 2000.

[14] O. Scarlat, S. Mihaiu, G. Aldica, M. Zaharescu, and J. R. Groza, "Enhanced properties of Tin(IV) oxide based materials by fieldactivated sintering," Journal of the American Ceramic Society, vol. 86, no. 6, pp. 893-897, 2003.
[15] J. R. Zhang, X. J. Xu, X. H. Li, L. Gao, and J. Sun, "Fabrication of antimony doped tin oxide ceramics by spark plasma sintering technique," Chinese Journal of Inorganic Chemistry, vol. 26, no. 6, pp. 1100-1104, 2010.

[16] V. Müller, M. Rasp, G. Śtefanić et al., "Highly conducting nanosized monodispersed antimony-doped tin oxide particles synthesized via nonaqueous sol-gel procedure," Chemistry of Materials, vol. 21, no. 21, pp. 5229-5236, 2009.

[17] Y. Q. Li, J. L. Wang, S. Y. Fu, S. G. Mei, J. M. Zhang, and K. Yong, "Facile synthesis of antimony-doped tin oxide nanoparticles by a polymer-pyrolysis method," Materials Research Bulletin, vol. 45, no. 6, pp. 677-681, 2010.

[18] D. Jain, K. M. Reddy, A. Mukhopadhyay, and B. Basu, "Achieving uniform microstructure and superior mechanical properties in ultrafine grained $\mathrm{TiB}_{2}-\mathrm{TiSi}_{2}$ composites using innovative multi stage spark plasma sintering," Materials Science and Engineering A, vol. 528, no. 1, pp. 200-207, 2010.

[19] V. Zamora, A. L. Ortiz, F. Guiberteau, and M. Nygren, "Sparkplasma sintering of $\mathrm{ZrB} 2$ ultra-high-temperature ceramics at lower temperature via nanoscale crystal refinement," Journal of the European Ceramic Society, vol. 32, pp. 2529-2536, 2012.

[20] O. Scarlat, M. Susana-Mihaiu, and M. Zaharescu, "Subsolidus phase relations in the $\mathrm{SnO}_{2}-\mathrm{CuSb}_{2} \mathrm{O}_{6}$ binary system," Journal of the European Ceramic Society, vol. 22, no. 11, pp. 1839-1846, 2002.

[21] D. G. Stroppa, L. A. Montoro, A. Beltran et al., "Dopant segregation analysis on $\mathrm{Sb}: \mathrm{SnO}_{2}$ nanocrystals," Chemistry A European Journal, vol. 17, pp. 11515-11519, 2011.

[22] I. Saadeddin, H. S. Hilal, B. Pecquenard et al., "Simultaneous doping of $\mathrm{Zn}$ and $\mathrm{Sb}$ in $\mathrm{SnO}_{2}$ ceramics: enhancement of electrical conductivity," Solid State Sciences, vol. 8, no. 1, pp. 7-13, 2006.

[23] L. E. Smart and E. A. Moore, Solid State Chemistry: An Introduction, CRC Press, 2005.

[24] J. Robertson and B. Falabretti, "Electronic structure of transparent conducting oxides," in Handbook of Transparent Conductors, D. S. Ginley, Ed., p. 27, Springer Science, Business Media, Limited liability company, 2010.

[25] U. Anselmi-Tamburini, S. Gennari, J. E. Garay, and Z. A. Munir, "Fundamental investigations on the spark plasma sintering/synthesis process: II. Modeling of current and temperature distributions," Materials Science and Engineering A, vol. 394, no. 1-2, pp. 139-148, 2005.

[26] T. Holland, U. Anselmi-Tamburini, D. V. Quacha, T. B. Trana, and A. K. Mukherjeea, "Effects of local Joule heating during the field assisted sintering of ionic ceramics," Journal of the European Ceramic Society, vol. 32, pp. 3667-3674, 2012.

[27] Y. J. Wu, J. Li, X. M. Chen, and K. Kakegawa, "Densification and microstructures of $\mathrm{PbTiO}_{3}$ ceramics prepared by spark plasma sintering," Materials Science and Engineering A, vol. 527, no. 20, pp. 5157-5160, 2010.

[28] L. Minier, S. Le Gallet, Y. Grin, and F. Bernard, "Influence of the current flow on the SPS sintering of a Ni powder," Journal of Alloys and Compounds, vol. 508, no. 2, pp. 412-418, 2010. 

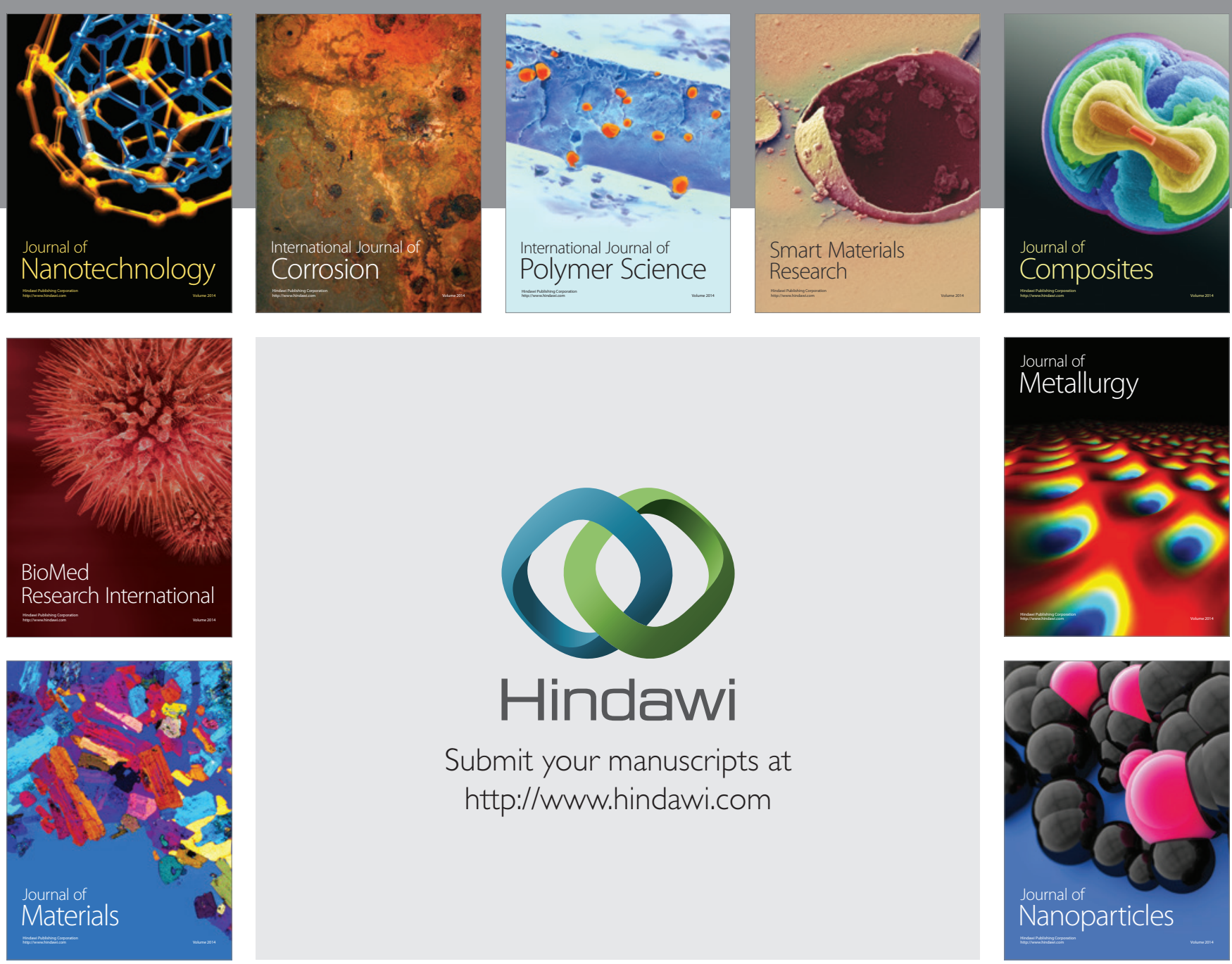

Submit your manuscripts at http://www.hindawi.com
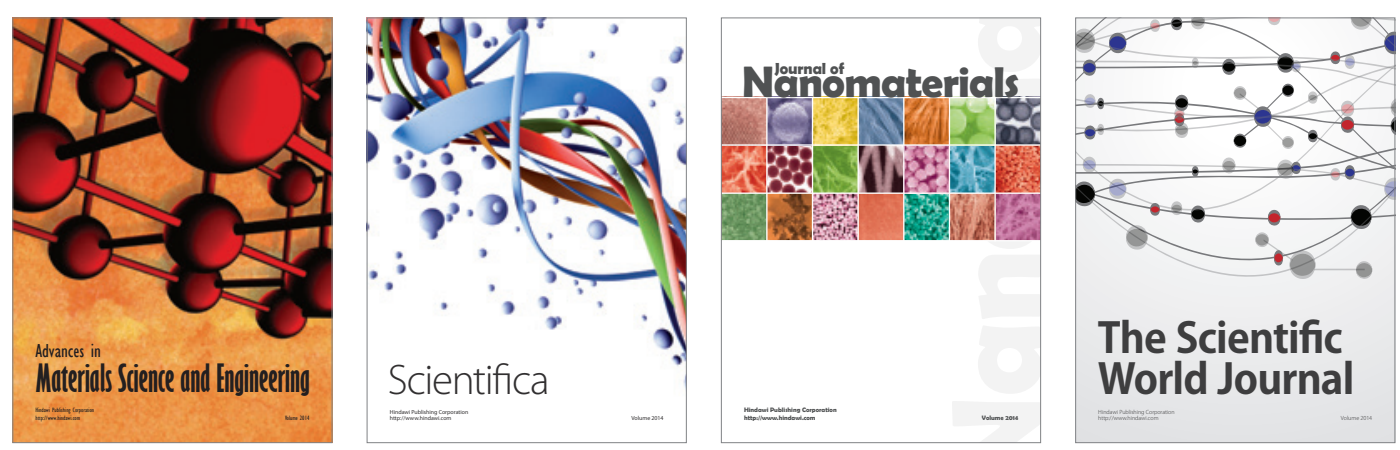

\section{The Scientific World Journal}
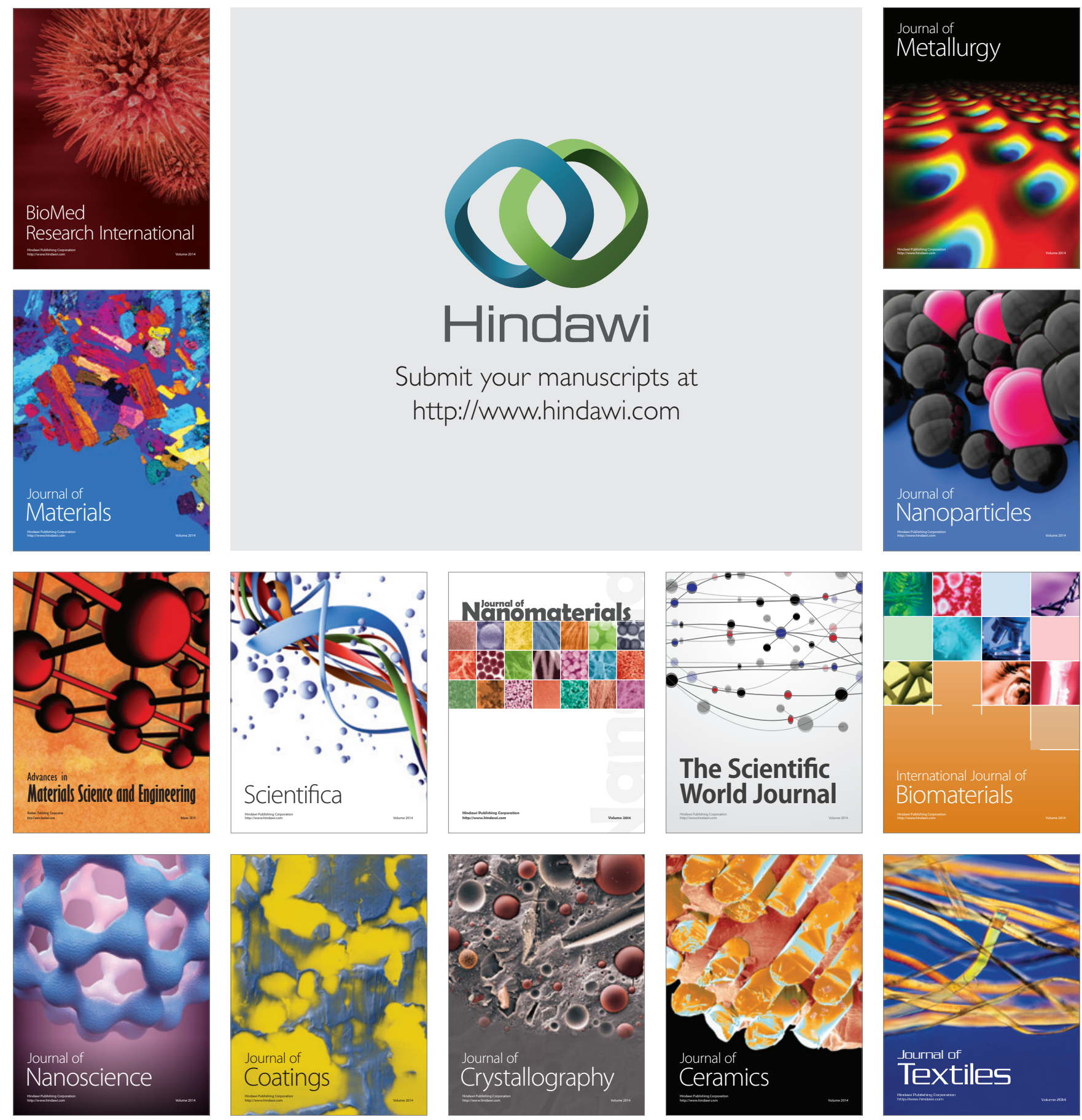